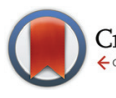

CrossMark $\leftarrow$ click for updates

Cite this: Polym. Chem., 2016, 7, 2272

Received 4th December 2015 Accepted 21st February 2016

DOI: 10.1039/c5py01937k

www.rsc.org/polymers

\title{
Green chain-shattering polymers based on a self-immolative azobenzene motif $\uparrow$
}

\author{
Hatice Mutlu ${ }^{a, b}$ and Christopher Barner-Kowollik*a,b
}

\begin{abstract}
A chain-shattering polymer system consisting of nontoxic, renewable resource-based monomers via acyclic diene metathesis (ADMET) chemistry is introduced. Amphiphilic triblock copolymers with apparent molecular weights in the range from 10 to $23 \mathrm{kDa}$ are synthesized using a monofunctional polyethylene glycol monoacrylate, which acts as a selective chain-transfer agent during the polymerization process. Most importantly, the functional polymers possess repetitive midchain azobenzene moieties imparting them with self-immolative properties. By virtue of the enzyme degradable azobenzene chain elements, the amphiphilic macromolecules can be efficiently degraded via a self-immolative reaction into small fragments. The construction of the macromolecules along with their degradation is evidenced by nuclear magnetic resonance spectroscopy, electrospray ionization mass spectrometry and size exclusion chromatography. In addition, the triggered degradation leads to a strong reduction in the UV absorptivity of the polymeric material.
\end{abstract}

\section{Introduction}

The current drive towards sustainable processes and environmental responsibility in macromolecular science requires alternative polymers with improved degradability based on renewable source-derived materials. ${ }^{1}$ The use of biomass, for instance castor oil or many other plant oils, has been recognized as one of the most promising routes, especially as a substitute source of chemicals which prospectively may replace the known diminishing petrochemicals. ${ }^{2}$ Importantly, degradation is not dependent on the origin of the building blocks but only on the chemical linkages present in the polymer. ${ }^{3}$ Nevertheless, one approach to obtain a biodegradable material in a sustainable fashion is to synthesize polymers constituted of a polymer backbone based on renewable source-derived components in which one or more degradable units (hydrodegradable, photodegradable or biodegradable) are embedded. ${ }^{4}$ However, the variety of degradation units in such materials remains limited. Thus, increasing the diversity of degradable polymers - including those derived from renewable resources - might allow for better matching soft matter materials to

\footnotetext{
${ }^{a}$ Preparative Macromolecular Chemistry, Institut für Technische Chemie und Polymerchemie, Karlsruhe Institute of Technology (KIT), Engesserstr. 18, 76131 Karlsruhe, Germany. E-mail: christopher.barner-kowollik@kit.edu ${ }^{b}$ Soft Matter Synthesis Laboratory, Institut für Biologische Grenzflächen (IBG), Karlsruhe Institute of Technology (KIT), Hermann-von-Helmholtz-Platz 1, 76344 Eggenstein-Leopoldshafen, Germany

$\dagger$ Electronic supplementary information (ESI) available: Synthesis and characterization details. See DOI: 10.1039/c5py01937k
}

specific applications. The azobenzene functionality is unique as it is capable of responding to changes in environmental conditions ${ }^{5}$ as well as being cleavable under an enzymatic impact (in vivo) via a two-electron reduction process. ${ }^{6,7}$ Despite the fact that azo containing compounds display a high structural diversity, the degradation is induced by specific enzymes, among which are azoreductases and glycosidases. ${ }^{6}$ While the azo bond reduction has been described in both anaerobic and aerobic bacteria, anaerobic conditions are prevalent in the human body. ${ }^{8,9}$ The operation of these enzymes has common mechanistic features as they all catalyse redox reactions and moreover exhibit relatively wide substrate specificities. ${ }^{6}$ More specifically, azoreductases - present and active both in the gut microflora and mammalian tissues (such as the skin $^{9}$ and the liver) $)^{10}$ - are redox cofactor $^{11}$ (i.e. flavin mononucleotide (FMN) or flavin adenine dinucleotide (FAD)) dependent enzymes that require the addition of a cofactor such as nicotinamide adenine dinucleotide phosphate $(\mathrm{NAD}(\mathrm{P}) \mathrm{H})$ as electron donors for the reduction of the azo linkage. Thus, the reductive cleavage of the azobenzene bond in the presence of azoreductase results in a self-immolative aniline derivative, which degrades entirely by intramolecular 1,6-elimination reactions via iminoquinone methide intermediates to 4-aminobenzyl alcohol, a by-product with low toxicity. ${ }^{12,13}$ The driving force is - in addition to the increase in entropy - the irreversible formation of $\mathrm{CO}_{2}$. Substantial efforts have been devoted to designing polymers incorporating azo moieties into the main chain including poly(ether ester), ${ }^{14}$ polyurethanes, ${ }^{15}$ and polyamides, ${ }^{16}$ however these are rarely discussed with regard to the structural features of the azo compound. The azo unit can 


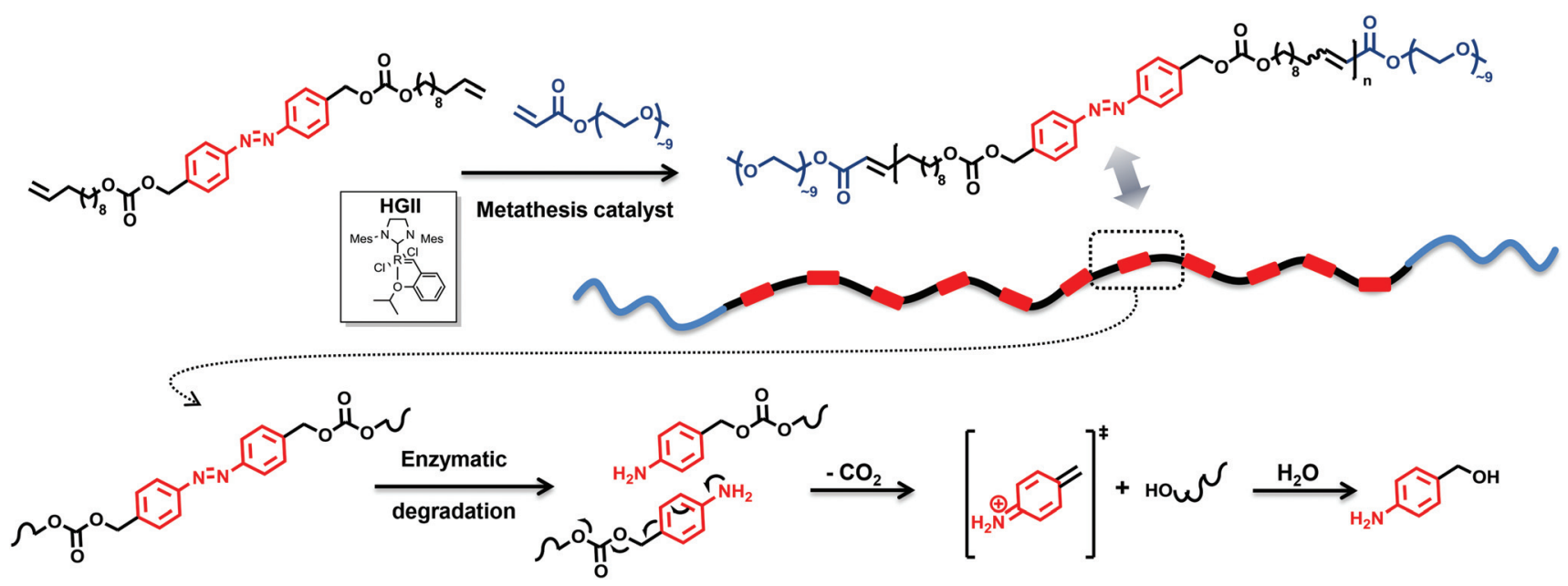

Fig. 1 Enzyme-responsive chain-shattering amphiphilic ADMET triblock copolymer containing multiple self-immolative degradable azobenzene moieties as a repetitive constraint.

accelerate the rate of reduction and in turn the degradation of the polymer in a self-immolative manner. Besides the typical self-immolative polymers end-capped with variable trigger responsive functional groups ${ }^{17}$ there are rare examples of selfimmolative polymeric systems which possess multiple triggers linked either as side chain motifs or directly within the backbone, termed chain-shattering polymers.

Chain-shattering polymers spontaneously disintegrate along the main chain into small components only after activation by a specific stimulus. The systems whose multiple triggers are connected as pendant groups are generally synthesized using classical step-growth copolymerization. Typically, activated bifunctional self-immolative linkers capped by a trigger are reacted in a step-growth manner with bifunctional comonomers to yield polymers which degrade either through a consecutive quinone methide rearrangement (via 1,4-/1,6-elimination) or intramolecular cyclization upon a specific stimulus. ${ }^{18}$ Alternatively, the toolbox for the synthesis of chainshattering polymers was expanded by employing chain-growth ring-opening polymerization $(\mathrm{ROP})^{19}$ and olefin metathesis chemistry $^{20}$ (specifically acyclic diene metathesis). However, none of the systems described above were targeted to develop a chain-shattering polymer whose enzyme-labile self-immolative triggers are directly incorporated as repetitive chain motifs within the polymer backbone. Thus, with the aim to critically diversify the available chain-shattering polymer toolbox and enlarge the variety of self-immolative monomers, we describe the development of the strategy presented in Fig. 1.

\section{Results and discussion}

The construction of polymers conjugated with triggers in the backbone from a building block with two terminal alkenes and an azo moiety serving as an enzyme-responsive group will result in elimination reactions at each repeating unit after the application of a trigger, here an enzyme. Thus, a depolymerisa- tion reaction will occur by means of a chain-shattering mechanism, thereby accelerating the depolymerisation. The challenge and innovation inherent to the current approach is the design of an enzyme-responsive polymer segment. Inspired by the synthetic possibilities to introduce repetitive constraining elements via acyclic diene metathesis (ADMET) polymerization, ${ }^{21}$ a precision polyolefin containing a degradable azobenzene moiety as a repetitive constraint (Fig. 1) is introduced. Indeed, Wagener has explored the use of this polymerization technique to elegantly synthesize precision polyolefins containing diverse functional groups. ${ }^{22}$ Moreover, Meier and colleagues used the ADMET polymerization of renewable biobased $\alpha, \omega$-dienes incorporating hydrodegradable linkages (such as anhydride, esters) ${ }^{23}$ to yield (bio)degradable polymers. Undoubtedly, fatty acids and their derivatives are suitable components for the preparation of (bio)degradable polymers since they are hydrophobic entities that naturally occur in the body, and their application as building blocks for such polymers introduces additional pliability. ${ }^{24}$ Thus, 10-undecene-1$\mathrm{ol}$, a subsidiary product of castor oil, ${ }^{2}$ was used as a renewablebased alcohol derivative for the synthesis of the self-immolative $\alpha, \omega$-diene monomer M1 (Fig. 2). The synthesis of a suitable monomer for ADMET polymerization was achieved by placing a carbonate moiety as a leaving group at the benzylic position of the azobenzene functionality in the hydroxyl alkene-based M1 (for preparative details refer to the ESI $\dagger$ ). Our efforts for ensuring the environmentally benign nature of $\mathbf{M 1}$ were not limited to biomass as a source. We employed glucose as a 'green' reducing agent for the synthesis of the azo derivative, 4,4'-bis(hydroxymethyl)-azobenzene (Fig. 2) starting from 4-nitrobenzyl alcohol. Moreover, the aforementioned nitro benzyl derivative was obtained via the oxone mediated oxidation of 4-aminobenzyl alcohol. ${ }^{25}$ In addition, 1,1-carbonyl diimidazole $(\mathrm{CDI})^{26}$ was used as a safe and non-toxic reagent to couple the azo diol moiety with 10-undecen-1-ol yielding the self-immolative $\alpha, \omega$-diene monomer M1 (Fig. 2). 


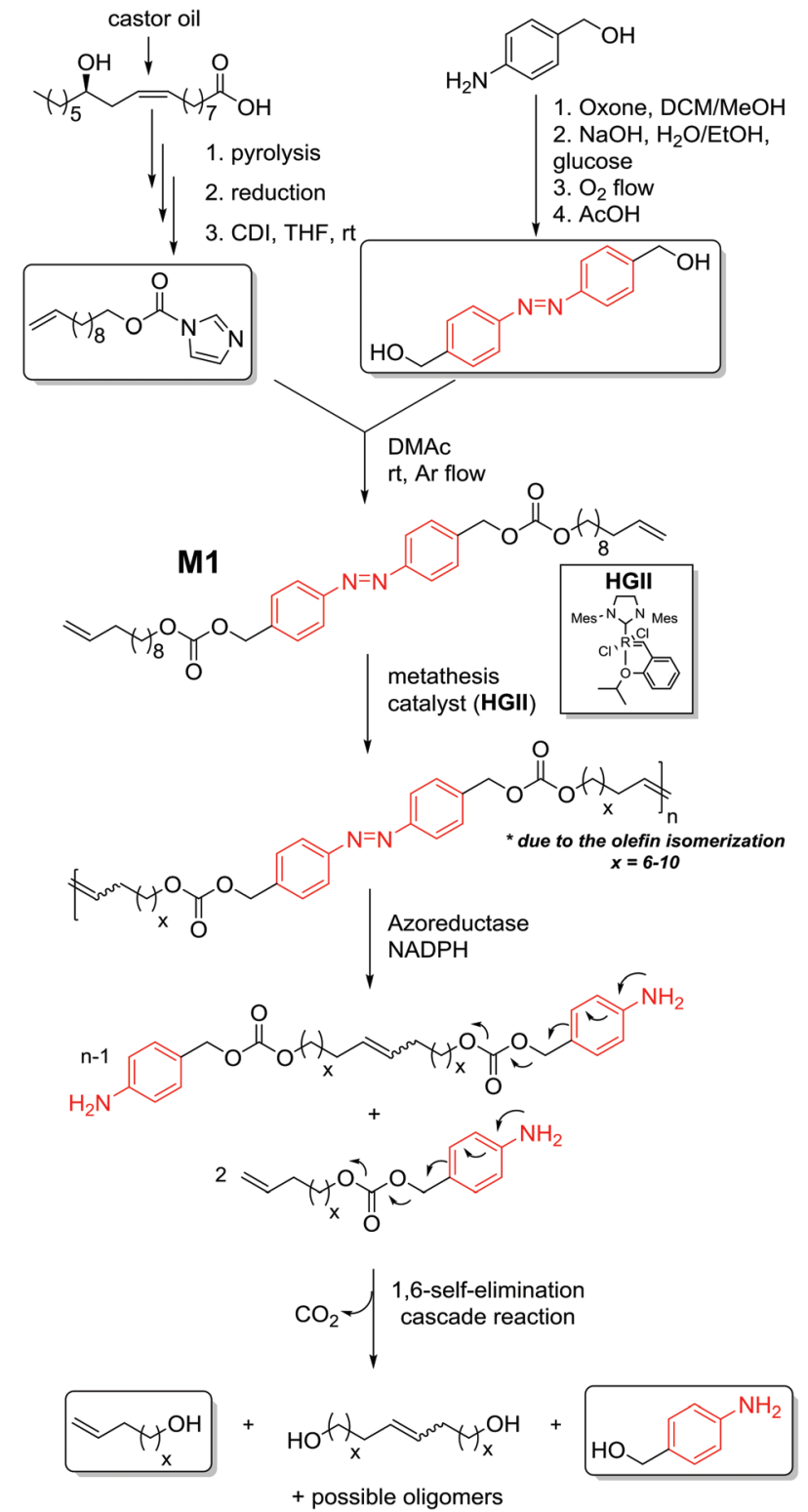

Fig. 2 Synthesis of the monomer, M1, possessing a self-immolative character and the respective ADMET polymer P1. The plausible cleavage of azobenzene linkages in P1 upon enzymatic action and subsequent 1,6-self elimination to smaller molecular weight species.

The synthesized azo derivative, $\alpha, \omega$-diene monomer M1, enabled the introduction of a degradable constraint every 20 carbons in the polymer obtained by ADMET chemistry. Polymer P1, with an apparent molar mass of $25 \mathrm{kDa}$ and with a dispersity of 2.0 (as determined by size exclusion chromatography (SEC) relative to polystyrene standards), was generated in the presence of $1 \mathrm{~mol} \%$ second-generation Hoveyda-Grubbs (HGII) catalyst per double bond (i.e. 2 mol\% HGII catalyst/ molecule) under reduced pressure (compare Fig. 2 and Table S1 in the ESI $\dagger$ ). HGII was the choice of catalyst due to its outstanding tolerance and activity toward coordinative and non-coordinative heteroatom containing dienes. ${ }^{27}$

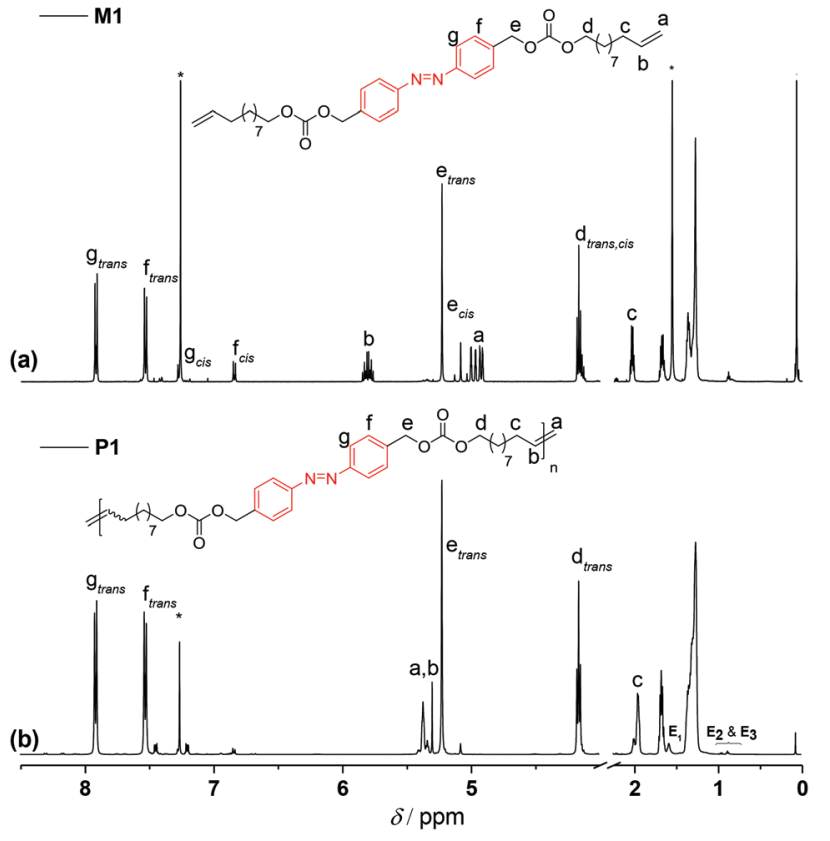

Fig. $3{ }^{1} \mathrm{H}$ NMR $\left(500 \mathrm{MHz}, \mathrm{CDCl}_{3}\right)$ spectra of (a) the azo derivative $\alpha, \omega$-diene monomer M1 and (b) of a representative homopolymer P1 (shown in Table S1 in the ESI $)$ ). The end groups associated with the olefin isomerization in the homopolymer P1 are indicated as E1, E2, and E3, respectively.

To remove the quenched metathesis catalyst from the crude polymer reaction mixture, the mixture was eluted with chloroform and passed through a short plug of silica/basic alumina. In comparison with the ${ }^{1} \mathrm{H}$ NMR of the corresponding monomer M1 (Fig. 3a), a clean and complete transformation of the $\alpha, \omega$-diene to the unsaturated polymer P1 was observed (Fig. 3b). ${ }^{1} \mathrm{H}$ NMR spectroscopic analysis of the polymer revealed resonances characteristic of the newly formed internal double bond at $\delta H 5.35 \mathrm{ppm}$. Furthermore, it is worth highlighting that along ${ }^{1} \mathrm{H}$ NMR, ${ }^{13} \mathrm{C}$ NMR analysis also demonstrated that the azo functionality remained intact, indicating the compatibility of ADMET chemistry with the azobenzene unit (compare Fig. S2 in the ESI $\dagger$ ).

To determine the distribution and the degree of polymerization $\left(\mathrm{DP}_{\mathrm{n}}\right)$ of the polymer, $\mathbf{P} \mathbf{1}$ was subjected to matrix assisted laser desorption ionization time-of-flight mass spectrometry. However, due to the broad dispersity of $\mathbf{P 1}$, initial attempts to obtain mass spectra representative of the complete distribution of the polymer failed. On the other hand, the undesired isomerization side reaction ${ }^{28}$ which usually occurs during ADMET polymerization facilitated to define the $\mathrm{DP}_{\mathrm{n}}$ by ${ }^{1} \mathrm{H}$ NMR via end-group resonance integration, yielding a $\mathrm{DP}_{\mathrm{n}}$ of 42 for P1 $\left(M_{\mathrm{n}}\right.$ of $25.5 \mathrm{kDa}$, refer to the NMR discussion part in the ESI $\dagger$ ). The end groups associated with the olefin isomerization are indicated as E1, E2, and E3, respectively (refer to the ${ }^{1} \mathrm{H}$ NMR assignments in Fig. 3). Commonly, additives such as benzoquinone $\mathrm{e}^{29}$ are used to suppress the isomerization, however any attempts to employ benzoquinone during the ADMET polymerization reactions failed. It has been reported 
that the azobenzene group does not undergo any 1,4-cycloaddition with benzoquinone, ${ }^{30}$ yet the polymers obtained from the polymerization of $\mathbf{M 1}$ in the presence of 1,4-benzoquinone were not completely soluble in common organic solvents, suggesting that some limited crosslinking reactions might have taken place.

In order to evaluate the efficiency of the anticipated elimination reactions in the new polymer system, the reductive cleavage of the azo functionality within $\mathbf{M 1}$ itself was assessed by NMR spectroscopic methods. $\mathrm{Na}_{2} \mathrm{~S}_{2} \mathrm{O}_{4}$, a substitute that mimics the azoreductase enzyme, was employed as the reducing agent. ${ }^{31}$ Upon treatment with 1 equivalent of the reducing agent in phosphate-buffered saline (PBS, $\mathrm{pH} 7.4$ ), ${ }^{32}$ the reaction was incubated at $37{ }^{\circ} \mathrm{C}$ for several hours. ${ }^{1} \mathrm{H}$ NMR analysis of the final reaction mixture showed far different results than expected, i.e. no degradation. The limited solubility of the hydrophobic M1 in PBS is identified as the main reason for the incomplete reduction. ${ }^{8}$ However, this attempt also clearly evidenced the hydrolytic stability of M1. To facilitate a complete reduction, a mixture of dichloromethane: methanol: water $(3: 20: 20)$, which has proven to be a useful solvent for the conversion of azobenzenes into $N, N^{\prime}$-diarylhydrazines, ${ }^{33}$ was employed to drive the reduction to the corresponding aniline derivative. By using 5.5 equivalents of $\mathrm{Na}_{2} \mathrm{~S}_{2} \mathrm{O}_{4}$, a loss of the characteristic strong yellow colour of $\mathbf{M 1}$ is detected within $40 \mathrm{~min}$, and the reduction was confirmed by UV-Vis and ${ }^{1} \mathrm{H}$ NMR (Fig. 4 and S3 in the main text and the ESI, $\uparrow$ respectively). The UV-visible absorption spectra of M1 were characterized by a band at $330 \mathrm{~nm}$, the intensity of which decreased gradually with time during the degradation process (Fig. 4). For the complete reduction, the necessary reaction time was $5 \mathrm{~h}$ in total.

Once the reduction of $\mathbf{M 1}$ had been established, the subsequent step was to perform reduction studies on the polymer itself. While $\mathrm{Na}_{2} \mathrm{~S}_{2} \mathrm{O}_{4}$ is a specific, bio-compatible ${ }^{34}$ and effective chemical stimulus that may be useful in some applications, it was also of interest to demonstrate that the

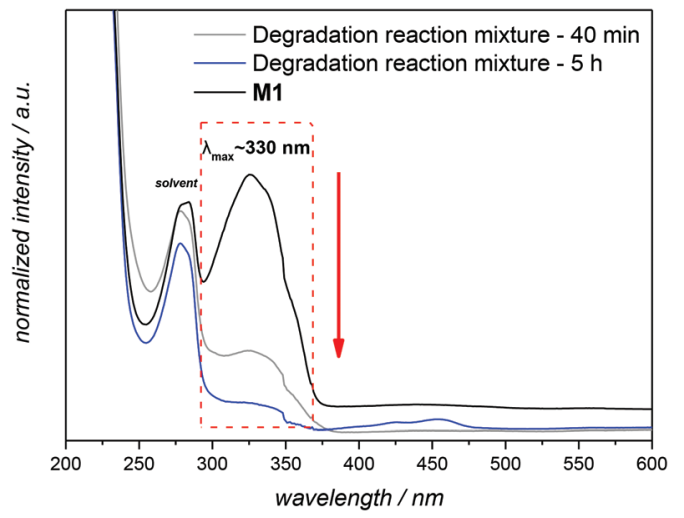

Fig. 4 UV-visible spectra illustrating the degradation of $M 1$ in the presence of 5.5 equivalents of $\mathrm{Na}_{2} \mathrm{~S}_{2} \mathrm{O}_{4}$ in a mixture of dichloromethane: methanol: water at reflux temperature (for details see section A.8 in the $\mathrm{ESI} \dagger$ ). Spectra recorded in THF at $25^{\circ} \mathrm{C}$. reduction of the specified system is possible under biologically relevant conditions, as this would significantly expand the utility of the polymer. Thus, the following experiments were conducted with the enzyme azoreductase (commercially known as DT-diaphorase) in the presence of the coenzyme NADPH.

The initial degradation studies were performed in the same manner as those previously reported by Khan et al., by suspending the ADMET polymer P1 in PBS, and subsequently exposing it to a mixture of the enzyme azoreductase and the coenzyme NADPH, followed by incubation at $37^{\circ} \mathrm{C}$ for a period of $12 \mathrm{~h}$. As noted, a crucial point in the reduction reactions is to avoid oxygen due to the fact that dioxygen can serve as an alternative electron acceptor, thus inhibiting the azoreductase activity. ${ }^{35}$ Accordingly, the reduction was performed under anaerobic conditions. To remove the cofactor and its byproducts, the solution was dialyzed against water. Unexpectedly, ${ }^{1} \mathrm{H}$ NMR and SEC analysis of P1' (Fig. S4 and S5 in the $\mathrm{ESI}, \dagger$ respectively) did not indicate any degradation, moreover no specific colour change was observed during the reaction. On the basis of the ${ }^{1} \mathrm{H}$ NMR analysis, the trans-cis isomerisation of the azo bond was detected as the only significant change (compare Fig. S4 in the ESI $\dagger$ ). Indeed, this transformation can be of particular interest for future studies in the context of the reduction-sensitive moiety due to the fact that cis azobenzene has an increased rate of reduction relative to the trans isomer. ${ }^{36}$ Nevertheless, having in mind that the specified enzyme can show 'degressive' prolonged stability under the aforementioned conditions, the influence of the reaction time was subsequently investigated. However, even after monitoring the degradation reaction over a period of 11 days $\left(\mathbf{P 1}{ }^{\prime \prime}\right)$, there was only a minimal decrease in the molecular weight of the polymer (due to a possibly competing hydrolytic mechanism) as observed in the SEC chromatogram of the isolated product (Fig. S6 in the ESI $\dagger$ ).

The ineffective degradation of P1 clearly indicates that to achieve the desired degradability, the polymer structure needs to be adjusted. Indeed, an advantage of the ADMET polymerization approach is the possibility to use olefins other than the terminal ones not only to introduce defined end groups but also as a way to obtain ABA triblock copolymers with finely selected solubility properties. Thus, a poly(ethylene glycol) (PEG) moiety possessing a methyl ether acrylate functionality, considered to be inert and possessing a low level of toxicity, ${ }^{37}$ can provide the desired water solubility. By incorporation of water soluble blocks in the polymer system, one can avoid the potential steric inhibition of the azoreductase. Thus, an amphiphilic copolymer was prepared under similar conditions to those for the ADMET homopolymer, but with the addition of a selective and irreversible chain-stopper (CS), a monofunctional PEG methyl ether acrylate $\left(M_{\mathrm{n}}=480 \mathrm{Da}\right)$ (compare Fig. 1, 2 and S7, respectively in the main text and the ESI $\dagger) .{ }^{38}$ The addition of variable amounts of CS (2, 5, 10 and $20 \mathrm{~mol} \%$, respectively) to the polymerization mixture led to efficient control of the molecular weight of the resulting polymers P2-P5 (see Fig. 5 as well as Table S1, entries 2-5 in the ESI $\dagger$ ), 


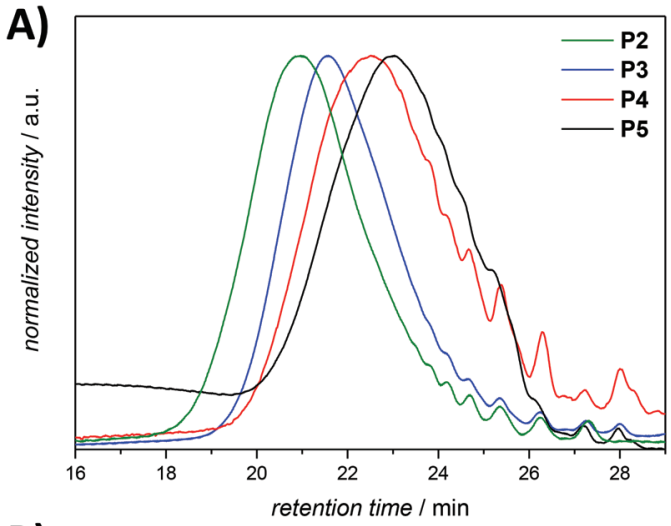

B)

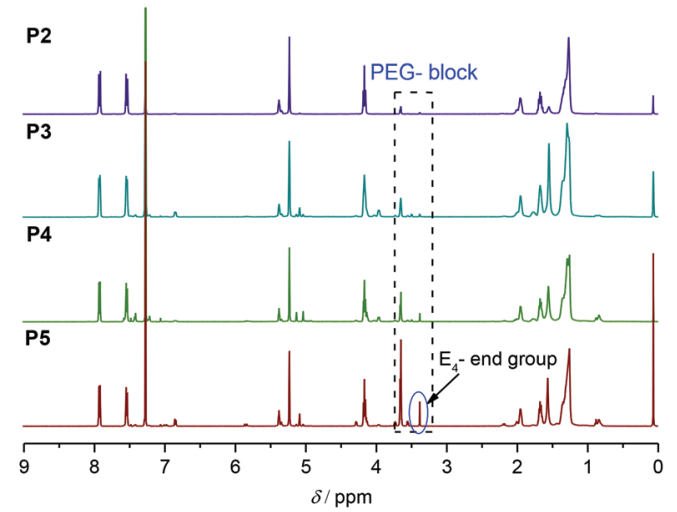

Fig. 5 (A) SEC chromatograms for ADMET amphiphilic triblock copolymers P2-P5 presented in Table S1 in the ESI. $\dagger$ The SEC traces were measured in THF at $30{ }^{\circ} \mathrm{C}$. (B) ${ }^{1} \mathrm{H}$ NMR $\left(500 \mathrm{MHz}, \mathrm{CDCl}_{3}\right)$ spectra of the amphiphilic triblock copolymers $\mathrm{P} 2-\mathrm{P} 5$ presented in Table $\mathrm{S} 1, \uparrow$ respectively. Refer to Fig. 3 for the assignment of key resonances associated within the aromatic region. The major end group associated with the olefin isomerization in the copolymers P2-P5 is indicated as E4.

thus resulting in defined amphiphilic ABA triblock copolymer architectures. The $M_{\mathrm{n}}$ values determined for the copolymers by SEC are slightly different compared with the theoretical ones (Table S1 in the ESI $\uparrow$ ), since SEC molecular weights were determined relative to the polystyrene (PS) standards. The ABA triblock copolymers were tested for their degradation behaviour. The triblock P4, synthesized with $10 \mathrm{~mol} \%$ CS in the presence of $1 \mathrm{~mol} \%$ second-generation Hoveyda-Grubbs (HGII) catalyst per double bond (i.e. $2 \mathrm{~mol} \%$ HGII catalyst/molecule) under reduced pressure, was subjected to the same degradation conditions as the homopolymer P1 for reaction times of 12, 24 and $36 \mathrm{~h}$, respectively. The degradation mixture of the polymer incubated for $36 \mathrm{~h}$ indicated a similar degree of degradation to that after $24 \mathrm{~h}$ (compare Fig. S8 in the ESI $\dagger$ ). We suggest that changes in the $\mathrm{pH}$ (from the initial $\mathrm{pH}$ value of 7.4 to 6.5) during the degradation due to increased $\mathrm{CO}_{2}$ levels in the sealed vials likely affected the degree of degradation. Indeed, $\mathrm{CO}_{2}$ is acidic in nature, thus a high $\mathrm{CO}_{2}$ saturation will lead to low $\mathrm{pH}$ and consequently reduce the activity of azoreductase, which is mainly active in the $\mathrm{pH}$ range of 5.5 to 8.3 (optimal reduction conditions being structure specific). ${ }^{39}$
A)

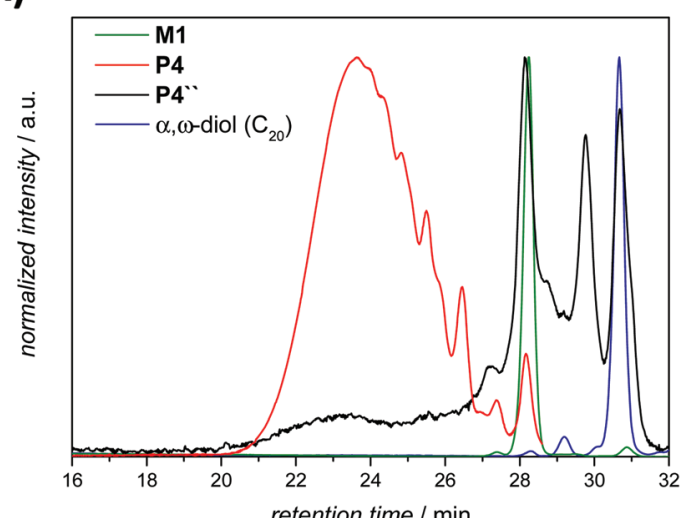

B)

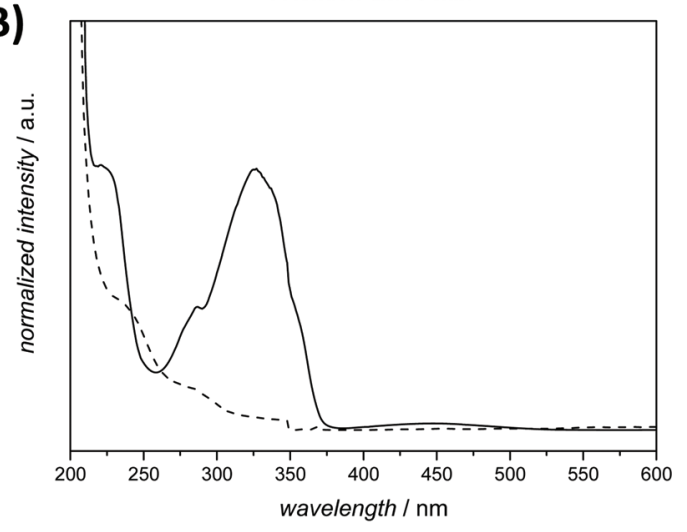

Fig. 6 (A) SEC chromatograms obtained in THF for monomer M1 (green line), polymer P4 (red line, due to an artefact of the measurement, the elugram finished at $28.6 \mathrm{~min}$ ), the resulting mixture after treatment with the enzyme for $24 \mathrm{~h}$ - P4" (black line), and the model degradation product $\alpha, \omega$-diol (blue line), respectively. (B) UV-Vis spectra of the polymer P4 (solid line) and the reaction mixture P4" after the enzymatic reaction and purified (dashed line). The sample concentration is $0.4 \mathrm{mg} \mathrm{mL}^{-1}$ in $\mathrm{CH}_{2} \mathrm{Cl}_{2}$. Solvent cut-off wavelengths $L_{0}$ : 245 and $L_{1}$ : $230 \mathrm{~nm}$, respectively $\left(\lambda_{\text {max }}: 253 \mathrm{~nm}\right.$ for $\mathrm{CH}_{2} \mathrm{Cl}_{2}$ ).

UV-vis spectroscopy analysis established a broad adsorption band at $330 \mathrm{~nm}$ for the amphiphilic triblock copolymer P4, which is typical of the azobenzene chromophore having a dihydroxy substitution pattern at the para-position. ${ }^{40}$ The examination of the purified degradation mixture after $24 \mathrm{~h}$ treatment, P4" by UV-vis spectroscopy confirmed that the azobenzene linkages were cleaved, as no absorption signal could be observed at $330 \mathrm{~nm}$ after the enzymatic treatment of polymer $\mathbf{P 4}$ (refer to Fig. 6B).

In addition, in the ${ }^{1} \mathrm{H}$ NMR spectra, resonances corresponding to the expected depolymerization products are observed to increase in intensity, while the resonances in the aromatic region associated with the polymer decreased (Fig. S9 in the ESI $\dagger$ ). Although SEC, UV-Vis and ${ }^{1} \mathrm{H}$ NMR spectroscopy evidence the successful degradation of the amphiphilic triblock copolymer, these data alone do not provide insight into the exact composition of the small molecule degradation fragments. Therefore, additional high resolution ESI-MS allowed assigning the degradation products, evidencing all possible 

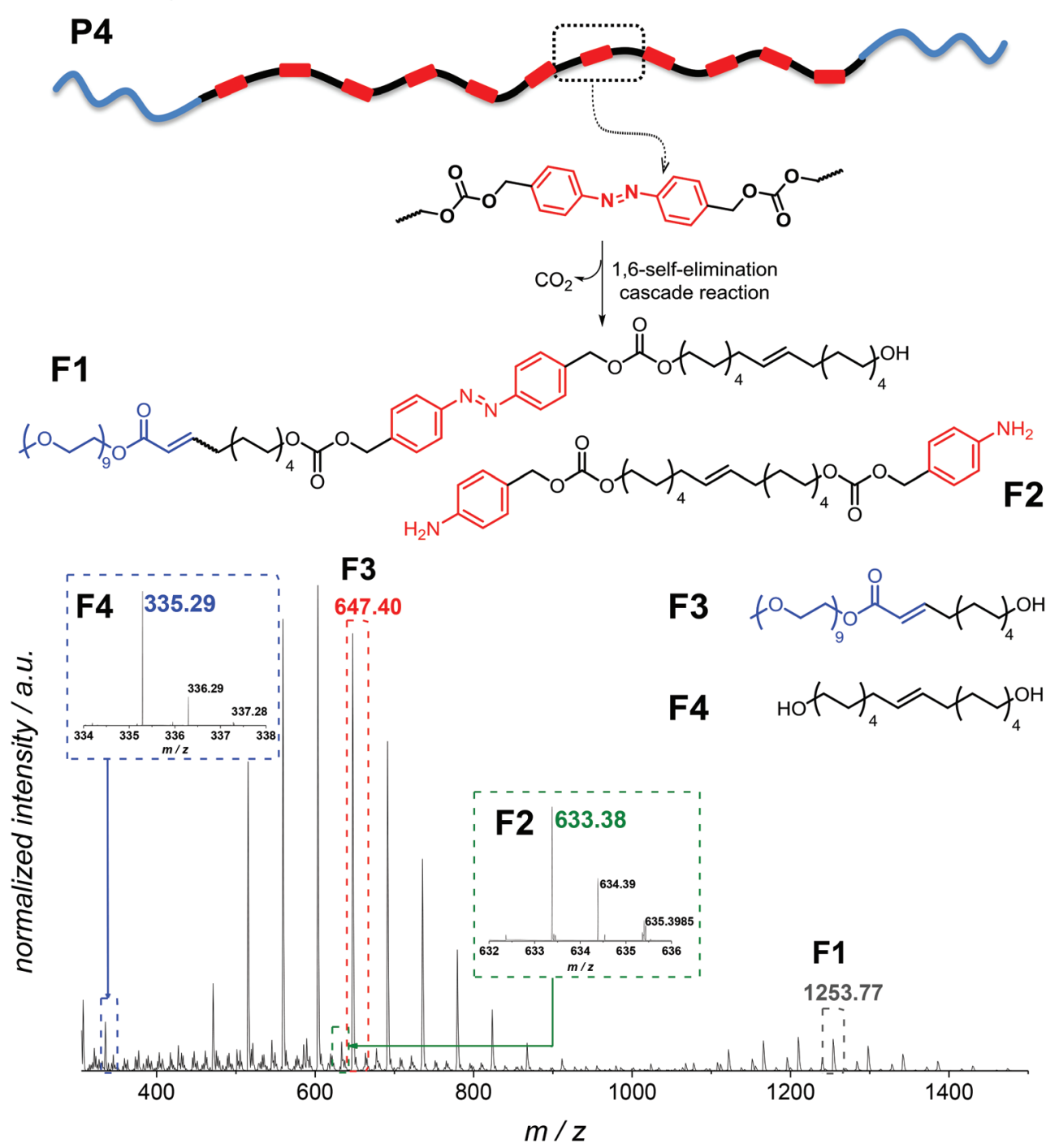

Fig. 7 High resolution ESI-MS analysis of the degradation fragments of P4 after enzymatic treatment for 24 h (P4").

fragments which can arise (Fig. 7). Analysis of a solution of P4" in $\mathrm{CH}_{2} \mathrm{Cl}_{2}: \mathrm{MeOH}(3: 1, \mathrm{v} / \mathrm{v})$ by using a Q-Exactive Orbitrap mass spectrometer indicated that F1-F4 (shown in Fig. 7) were the major degradation products, suggesting that the desired degradation occurred at the majority of the self-immolative repeating units. Surprisingly, both the $\alpha, \omega$-diol $\left(\mathbf{F 4}, \mathrm{m} / \mathrm{z}_{\text {calc }}=\right.$ 335.29, $\left.[\mathrm{M}+\mathrm{Na}]^{+}\right)$and the unstable species $\mathbf{F} 2\left(\mathrm{~m} / \mathrm{z}_{\text {calc }}=\right.$ 633.38, $[\mathrm{M}+\mathrm{Na}]^{+}$), before its 1,6-elimination to form F4, were detected. Moreover, we were able to detect the fragment F1 $\left(m / z_{\text {calc }}=1253.77,[\mathbf{M}+\mathrm{Na}]^{+}\right)$before its self-immolation to $\mathbf{F 3}$ $\left(\mathrm{m} / z_{\text {calc }}=647.40,[\mathrm{M}+\mathrm{Na}]^{+}\right)$, which is the hydrophilic block of the polymer P4. Therefore, the mass difference between the parent ion $\mathrm{m} / \mathrm{z} 1253.7646$ and the product ion $\mathrm{m} / \mathrm{z} 647.3977$ can be tentatively assigned to the repeating unit of the hydrophobic part of the triblock copolymer $\mathbf{P 4}$ with a nominal mass of 606.3669 Da. The fragments F1 and F3 show the typical PEG pattern with mass distributions of the adjacent peaks separated by $44.08 \mathrm{Da}$, corresponding to the mass of the repeat unit, ethylene oxide. ${ }^{41}$ In addition, the expected compound with $m / z 123.07$ (4-aminobenzyl alcohol) was not detected. However, as demonstrated by using a standard of 4-aminobenzyl alcohol, this compound is not stable under the experimental conditions (MS), and several coupling reactions could have taken place.

To confirm that the observed degradation products are associated with the proposed 1,6-elimination reaction, control reactions were performed with polymer $\mathbf{P 4}$ in water without any reducing agent for a period of $24 \mathrm{~h}$ (compare the SEC traces in Fig. S10 in the ESI $\dagger$ ). Although the control reaction indicates a slight shift compared to the initial polymer P4, it is clear that the proposed reductive/self-immolative mechanism is dominant in comparison with a possibly competing hydrolytic mechanism, which is largely inoperational unless the exposure time is very long (compare Fig. S6 in the ESI $\dagger$ ). 


\section{Conclusions}

In summary, we introduce a strategy for the synthesis of renewable resource-based amphiphilic ADMET polymers which possess self-immolative degradable enzyme-triggered azobenzene units, thus establishing a new class of chainshattering polymers. Upon treatment with an enzyme and a coenzyme, the azo units were transformed into amine groups, which triggered the sequential self-immolative process to degrade the polymer main chain. The in situ formed quinone methide intermediates were quenched by water molecules to form stable and safe hydroxymethylphenol derivatives. The degradation of the introduced system contrasts with conventional self-immolative polymers, which degrade from one chain end to the other. The chemistry of the system is unique since the polymer degrades from the trigger cleavage side to its tail. In addition, the enzyme employed for the degradation, DT-diaphorase, does not form any free-radical or reactive oxygen intermediates during the degradation process. The developed systems thus open the prospect to function as delivery vehicles in cancer cells/tissues in the human body which show higher turnovers of NADPH than in normal cells/ tissues. ${ }^{42}$ The introduced system is a prime example of a stimuli responsive biodegradable polymer and future studies will investigate the applicability of the new polymeric material for single chain nanoparticle synthesis ${ }^{43}$ for applications in imaging and delivery.

\section{Acknowledgements}

C. B.-K. acknowledges support for the current project in the context of the Biointerfaces in Technology and Medicine program (BIFTM) of the Helmholtz association as well as the Karlsruhe Institute of Technology (KIT). Additional funding from the German Research Council (Large Equipment Scheme) is acknowledged. The authors thank Prof. Michael A. R. Meier (KIT) for GC-MS access and Dr Ana Beloqui Elizazu (KIT) for the fruitful discussion on the enzymatic degradation experiments.

\section{Notes and references}

1 K. Yao and C. Tang, Macromolecules, 2013, 46, 1689.

2 H. Mutlu and M. A. R. Meier, Eur. J. Lipid Sci. Technol., 2010, 112, 10.

3 K. E. Uhrich, S. M. Cannizaro, R. S. Langer and K. M. Shakesheff, Chem. Rev., 1999, 99, 3181.

4 M. Mitrus, A. Wojtowicz and L. Moscicki, in Thermoplastic Starch, Wiley-VCH Verlag GmbH \& Co. KGaA, 2010, pp. 1-33; R. R. Karlsson and A.-C. Albertsson, Polym. Eng. Sci., 1998, 38, 1251.

5 T. Shang, K. A. Smith and T. A. Hatton, Langmuir, 2003, 19, 10764; L. Ding, M. Xu, J. Wang, Y. Liao and J. Qiu, Polymer, 2014, 55, 1681.
6 For detailed mechanistic information on such enzymatic degradation: J. Chacko and K. Subramaniam, Int. J. Environ. Sci., 2011, 1, 1250; K. Golka, S. Kopps and Z. W. Myslak, Toxicol. Lett., 2004, 151, 203.

7 J. P. Brown, G. V. McGarraugh, T. M. Parkinson, R. E. Wingard and A. B. Onderdonk, J. Med. Chem., 1983, 26, 1300; M. Saffran, G. S. Kumar, C. Savariar, J. C. Burnham, F. Williams and D. C. Neckers, Science, 1986, 233, 1081; J. Kopeček, P. Kopečková, H. Brondsted, R. Rathi, B. Rihova, P.-Y. Yeh and K. Ikesue, J. Controlled Release, 1992, 19, 121; G. Van den Mooter, C. Samyn and R. Kinget, Int. J. Pharm., 1992, 87, 37; S.-Q. Gao, Z.-R. Lu, B. Petri, P. Kopečková and J. Kopeček, J. Controlled Release, 2006, 110, 323; J. Rao and A. Khan, J. Am. Chem. Soc., 2013, 135, 14056; J. Rao, C. Hottinger and A. Khan, J. Am. Chem. Soc., 2014, 136, 5872; A. D. Wong, T. M. Güngör and E. R. Gillies, ACS Macro Lett., 2014, 3, 1191; J. Rao and A. Khan, Polym. Chem., 2015, 6, 686.

8 A. Stolz, Appl. Microbiol. Biotechnol., 2001, 56, 69.

9 R. L. Stingley, W. Zou, T. M. Heinze, H. Chen and C. E. Cerniglia, J. Med. Microbiol., 2010, 59, 108.

10 C. N. Martin and J. C. Kennelly, Carcinogenesis, 1981, 2, 307.

11 S. Deller, P. Macheroux and S. Sollner, Cell. Mol. Life Sci., 2008, 65, 141.

12 The resulting amines are then generally excreted from the body; the less soluble amines, which may be absorbed through the intestinal lining, are processed in the liver before reaching the large intestine.

13 P. H. Houba, E. Bouven, C. A. Erkelens, R. G. Leenders, J. W. Scheeren, H. M. Pinedo and H. J. Haisma, Br. J. Cancer, 1998, 78, 1600; S. H. Lee, E. Moroz, B. Castagner and J.-C. Leroux, J. Am. Chem. Soc., 2014, 136, 12868.

14 W. Kalala, R. Kinget, G. Van den Mooter and C. Samyn, Int. J. Pharm., 1996, 139, 187.

15 Y. Kimura, Y. Makita, T. Kumagai, H. Yamane, T. Kitao, H. Sasatani and S.-I. Kim, Polymer, 1992, 33, 5294; T. Yamaoka, Y. Makita, H. Sasatani, S.-I. Kim and Y. Kimura, J. Controlled Release, 2000, 66, 187.

16 E. Schacht, A. Gevaert, E. R. Kenawy, K. Molly, W. Verstraete, P. Adriaensens, R. Carleer and J. Gelan, J. Controlled Release, 1996, 39, 327.

17 A. Sagi, R. Weinstain, N. Karton and D. Shabat, J. Am. Chem. Soc., 2008, 130, 5434; W. Wang and C. Alexander, Angew. Chem., Int. Ed., 2008, 120, 7921; C. A. Blencowe, A. T. Russell, F. Greco, W. Hayes and D. W. Thornthwaite, Polym. Chem., 2011, 2, 773; S. T. Phillips and A. M. DiLauro, ACS Macro Lett., 2014, 3, 298 and references therein; G. I. Peterson, M. B. Larsen and A. J. Boydston, Macromolecules, 2012, 45, 7317; S. Gnaim and D. Shabat, Acc. Chem. Res., 2014, 47, 2970; J. A. Kaitz, O. P. Lee and J. S. Moore, MRS Commun., 2015, 5, 191; A. Alouane, R. Labruère, T. Le Saux, F. Schmidt and L. Jullien, Angew. 
Chem., Int. Ed., 2015, 127, 7600; M. E. Roth, O. Green, S. Gnaim and D. Shabat, Chem. Rev., 2016, 116, 1309.

18 N. Fomina, C. McFearin, M. Sermsakdi, O. Edigin and A. Almutairi, J. Am. Chem. Soc., 2010, 132, 9540; C. de Gracia Lux, S. Joshi-Barr, T. Nguyen, E. Mahmoud, E. Schopf, N. Fomina and A. Almutairi, J. Am. Chem. Soc., 2012, 134, 15758; C. de Gracia Lux, C. L. McFearin, S. JoshiBarr, J. Sankaranarayanan, N. Fomina and A. Almutairi, ACS Macro Lett., 2012, 1, 922; Y. Zhang, Q. Yin, L. Yin, L. Ma, L. Tang and J. Cheng, Angew. Chem., Int. Ed., 2013, 125, 6563; Y. Zhang, L. Ma, X. Deng and J. Cheng, Polym. Chem., 2013, 4, 224; C. de Gracia Lux, J. Olejniczak, N. Fomina, M. L. Viger and A. Almutairi, J. Polym. Sci., Part A: Polym. Chem., 2013, 51, 3783; B. Fan, J. F. Trant, A. D. Wong and E. R. Gillies, J. Am. Chem. Soc., 2014, 136, 10116.

19 C. de Gracia Lux and A. Almutairi, ACS Macro Lett., 2013, 2, 432; J. Olejniczak, M. Chan and A. Almutairi, Macromolecules, 2015, 48, 3166; F.-Y. Qiu, C.-C. Song, M. Zhang, F.-S. Du and Z.-C. Li, ACS Macro Lett., 2015, 4, 1220.

20 A. Lv, Z.-L. Li, F.-S. Du and Z.-C. Li, Macromolecules, 2014, 47, 7707.

21 H. Mutlu, L. M. de Espinosa and M. A. R. Meier, Chem. Soc. Rev., 2011, 40, 1404.

22 S. E. Lehman Jr. and K. B. Wagener, in Handbook of Metathesis, Wiley-VCH, Weinheim, Germany, 2003, pp. 283-353 and references therein; T. W. Baughman and K. B. Wagener, in Advances in Polymer Science, Springer, Heidelberg, Germany, 2005, pp. 1-42; E. B. Berda and K. B. Wagener, in Polymer Science: A Comprehensive Reference, Elsevier BV, Amsterdam, Netherlands, 2012, pp. 195-216; E. B. Berda and K. B. Wagener, in Synthesis of Polymers; New Structures and Methods, Wiley-VCH, Weinhein, Germany, 2012, pp. 587-600; P. Atallah, K. B. Wagener and M. D. Schulz, Macromolecules, 2013, 46, 4735; C. Simocko, P. Atallah and K. B. Wagener, Curr. Org. Chem., 2013, 17, 2749; N. F. Sauty, L. C. da Silva, M. D. Schulz, C. S. Few and K. B. Wagener, Appl. Petrochem. Res., 2014, 4, 225.

23 O. Türünc and M. A. R. Meier, Green Chem., 2011, 13, 314; P. A. Fokou and M. A. R. Meier, J. Am. Chem. Soc., 2009, 131, 1664.

24 M. Sokolsky-Papkov, A. Shikanov, N. Kumar, B. Vaisman and A. J. Domb, Bull. Isr. Chem. Soc., 2008, 23, 12.

25 P. S. Mukherjee, N. Das, Y. K. Kryschenko, A. M. Arif and P. J. Stang, J. Am. Chem. Soc., 2004, 126, 2464.

26 S. P. Rannard and N. J. Davis, Org. Lett., 1999, 1, 933.

27 T. Lebarbé, A. S. More, P. S. Sane, E. Grau, C. Alfos and H. Cramail, Macromol. Rapid Commun., 2014, 35, 479;
K. Terada, E. B. Berda, K. B. Wagener, F. Sanda and T. Masuda, Macromolecules, 2008, 41, 6041; F. N. Führer and H. Schlaad, Macromol. Chem. Phys., 2014, 215, 2268; A. Tüzün, G. Lligadas, J. C. Ronda, M. Galia and V. Cadiz, Eur. Polym. J., 2015, 67, 503.

28 B. Schmidt, Eur. J. Org. Chem., 2004, 1865.

29 S. H. Hong, D. P. Sanders, C. W. Lee and R. H. Grubbs, J. Am. Chem. Soc., 2005, 127, 17160.

30 J. M. Fontan, Ph.D. thesis, University of Madrid, 1948.

31 X. Li, J. Li, Y. Gao, Y. Kuang, J. Shi and B. Xu, J. Am. Chem. Soc., 2010, 132, 17707; G. Leriche, G. Budin, L. Brino and A. Wagner, Eur. J. Org. Chem., 2010, 2010, 4360; Y. Y. Yang, M. Grammel, A. S. Raghavan, G. Charron and H. C. Hang, Chem. Biol., 2010, 17, 1212; J. B. Denny and G. Blobel, Proc. Natl. Acad. Sci. U. S. A., 1984, 81, 5286; J. M. Bergen, E. J. Kwon, T. W. Shen and S. H. Pun, Bioconjugate Chem., 2008, 19, 377; O. A. Kucherak, S. Oncul, Z. Darwich, D. A. Yushchenko, Y. Arntz, P. Didier, Y. Mely and A. S. Klymchenko, J. Am. Chem. Soc., 2010, 132, 4907.

32 M. W. Jones, G. Mantovani, C. A. Blindauer, S. M. Ryan, X. Wang, D. J. Brayden and D. M. Haddleton, J. Am. Chem. Soc., 2012, 134, 7406.

33 L. K. Sydnes, S. Elmi, P. Heggen, B. Holmelid and D. Malthe-Sørensen, Synlett, 2007, 1695.

34 G. Leriche, G. Budin, Z. Darwich, D. Weltin, Y. Mely, A. S. Klymchenko and A. Wagner, Chem. Commun., 2012, 48, 3224.

35 F. Rafii, W. Franklin and C. E. Cerniglia, Appl. Environ. Microbiol., 1990, 56, 2146.

36 C. Boulègue, M. Löweneck, C. Renner and L. Moroder, ChemBioChem, 2007, 8, 591.

37 V. S. Chadwich, S. F. Phillips and A. F. Hoffman, Gastroenterology, 1977, 73, 241; C. Fruijtier-P€olloth, Toxicology, 2005, 214, 1; R. P. Gullapalli and C. L. Mazzitelli, Int. J. Pharm., 2015, 496, 219.

38 A. Rybak and M. A. R. Meier, ChemSusChem, 2008, 1, 542.

39 H. E. Johansson, M. K. Johansson, A. C. Wong, E. S. Armstrong, E. J. Peterson, R. E. Grant, M. A. Roy, M. V. Reddington and R. M. Cook, Appl. Environ. Microbiol., 2011, 77, 4223.

40 L. Wu, Y. He and X. Tang, Bioconjugate Chem., 2015, 26, 1070.

41 R. Chen and L. Li, J. Am. Soc. Mass Spectrom., 2001, 12, 832.

42 S. K. Jonas, C. Benedetto, A. Flatman, L. Micheletti, C. Riley, P. A. Riley, D. Spargo, M. Zonca and T. F. Slater, Br. J. Cancer, 1992, 66, 185.

43 J. Willenbacher, K. N. R. Wuest, J. O. Mueller, M. Kaupp, H.-A. Wagenknecht and C. Barner-Kowollik, ACS Macro Lett., 2014, 3, 574. 